\title{
Reassessing the population based Seroprevalence for IgG antibodies against SARS COV2 in Ahmedabad
}

\author{
Om Prakash', Bhavin Solanki², Jay Sheth ${ }^{3}$, Ashwin Kharadi ${ }^{4}$, Mina Kadam ${ }^{5}$, \\ Sheetal Vyas ${ }^{6}$, Aparajita Shukla ${ }^{7}$, Hemant Tiwari ${ }^{8}$ \\ ${ }^{1}$ Deputy Municipal Commissioner, ${ }^{2}$ Medical Officer of Health, ${ }^{4}$ Deputy Health Officer, Ahmedabad Municipal Corporation \\ ${ }^{3}$ Associate Professor, ${ }^{6}$ Professor and Head, Department of Community Medicine, AMC MET Medical College, \\ Ahmedabad, ${ }^{5}$ Professor and Head, Department of Microbiology, AMC MET Medical College, Ahmedabad, ${ }^{7}$ Professor \\ and Head, ${ }^{8}$ Assistant Professor (Statistics), Community Medicine Department, Smt NHL Municipal Medical College, \\ Ahmedabad
}

\section{A B S T R A C T}

Background: Assessing population based seroprevalence can help in monitor the pandemic, and suggest appropriate corrective public health measures. Aims and Objectives: To study seroprevalence of IgG antibodies against SARS-CoV2 to understand the pandemic status and deriving valid conclusions for guiding the public health measures for managing the covid 19 pandemic. Materials and Methods: A serosurveillance study was carried out using population based stratified sampling for the general population of Ahmedabad city. Seroprevalence for Cases, Contacts and Health Care Workers (HCWs) was also estimated as separate additional categories. The seroprevalence was compared with various demographic factors for valid and precise predictions regarding the immunity status of the population. Results: As on October 2020, the seroprevalence for IgG antibodies against SARS-CoV2 in the general population of Ahmedabad is $24.20 \%$ ( $95 \%$ Confidence Interval $23.57 \%-24.85 \%$ ) The sero-positivity has increasing trend with age and is higher among females $(24.83 \%)$ than males $(23.72 \%)$ but is statistically not significant. The zone wise positivity ranged from $18.70 \%$ to $33.52 \%$. The seropositivity among HCWs, contacts and cases are $20.84 \%, 26.05 \%$ and $54.51 \%$ respectively and it closely correlate with the risk. Conclusion: As on October 2020, general population demonstrate a seropositivity of $24.20 \%$. The seropositivity among various groups is according to the risk of contracting the disease. Results also indicate the possibility of undetectable level or disappearing IgG during the post-covid period. Results also indicate that the preventive measures must be strongly followed for continued control of the pandemic Access this article online

Website:

http://nepjol.info/index.php/AJMS DOI: 10.3126/ajms.v12i5.35099

E-ISSN: 2091-0576

P-ISSN: 2467-9100

Copyright (c) 2021 Asian Journal of Medical Sciences

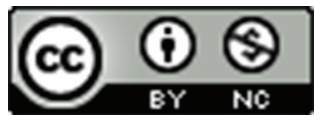

This work is licensed under a Creative Commons Attribution-NonCommercial 4.0 International License.

Key words: SARS-COV2; Covid-19, Sero-surveillance; Immunity; IgG Antibody

\section{INTRODUCTION}

During 2020, a novel virus - SARS-CoV2 spread across the world in pandemic proportion. ${ }^{1,2}$ For a newly identified agent, WHO has suggested monitoring of sero-prevalence. ${ }^{3}$ This is to understand the disease dynamics in a better way \& to plan an appropriate public health response. ${ }^{4}$ Looking to monitor the pandemic, understand its present situation and to take appropriate corrective public health measures, the Indian Council of Medical Research (ICMR) issued directives to all the state governments to carry out IgG ELISA test for sero-surveys along with ILI \& SARI Surveillance. $^{5}$

Ahmedabad city, in the state of Gujarat, INDIA, with approximately 7 million population was one of the first few cities to experience high number of cases during the initial months of the pandemic in India. Ahmedabad had already registered 36926 Covid-19 cases and 1816 reported Covid-19 deaths as on $15^{\text {th }}$ October 2020, before start of this study. 
Earlier, during the second half of June and First week of July, the Health department of AMC carried out its first sero-survey on 29891 samples. The second sero-survey was carried out during the second half of August 2020, on 10310 samples from general population, which additionally included samples from cases, contacts of cases and health care workers (HCW) also. The present study was planned in view of the ICMR directives, with the same methodology using the same testing kit - "Covid-Kavach" with higher sample size for higher precision as well as reliability with following aim and objectives.

\section{Aim}

- To estimate the seroprevalence for $\operatorname{Ig} G$ antibodies against SARS-CoV2 in Ahmedabad city.

\section{Objectives}

- To measure the level of seropositivity for Covid19 in the different population groups of Ahmedabad city

- To correlate the seropositivity with various factors for better understanding of the pandemic situation

- To understand the change in the immunity status for valid $\&$ precise predictions for the future.

\section{MATERIALS AND METHODS}

Indian Council of Medical Research (ICMR) had issued directives for conducting sero-surveillance using $\operatorname{IgG}$ Antibody based ELISA test to monitor the pandemic, understand its progression and to take appropriate corrective public health measures. ${ }^{5}$ ICMR has also emphasized on periodic sero-survey to guide the policy makers \& the present study is the $3^{\text {rd }}$ such serosurvey in Ahmedabad.

Earlier, Ahmedabad Municipal Corporation (AMC), from the state of Gujarat, INDIA, had already completed its first large scale population based sero-surveillance for IgG antibodies against SARS-CoV-2 with an average sero-positivity of $17.61 \% .^{6} \mathrm{~A}$ repeat population based sero-survey was again carried out during the second half of August 2020 with an average sero-positivity of $23.24 \%$. After a further gap of 2 months, another serosurvey was planned during the second half of October 2020. Considering the seroprevalence from earlier studies in a population of 70 lakh with $99 \%$ confidence level with $1 \%$ margin of error, the estimated sample size was 16600 . The sample is further stratified based on UPHC wise population, rounded upto next "0" to decide additional samples from other categories (Cases, contacts and HCW) and thus atleast 17000 samples from general population was planned. The positivity among Cases, Contacts of cases and HCWs is crucial in determining the dimension of susceptibility, transmissibility and effectiveness of protective measures followed. So, $10 \%$ of general population sample for each of these 3 categories was additionally collected for the purpose of our study.

"Covid Kavach"(Anti-SARS CoV-2 IgG Antibody Detection ELISA) kits developed and manufactured by Zydus Diagnostics, validated by National Institute of Virology, Pune, India and its use was approved by the Indian Council of Medical Research (ICMR) was used. Results of Covid-Kavach are highly reliable as per the validation reports, which have documented sensitivity of $92.37 \%$ and specificity of $97.9 \%{ }^{7}$ The manufacturer reported no cross-reactivity with other viruses in the serum from RTPCR confirmed patients of various other infections. Testing procedures were followed as per the manufacturer's instructions. For each plate, samples with optical density $(\mathrm{OD})$ value more than the cut-off value and positive/negative $(\mathrm{P} / \mathrm{N})$ ratio more than 1.5 were considered as positive. Samples with OD value of 10 per cent \pm ranges of the cut-off were considered to be indeterminate. The $\mathrm{P} / \mathrm{N}$ ratio was defined as the ratio of average OD value of the positive control divided by the average OD of the negative control. The cut-off OD value was calculated as the average $O D$ value of negative control +0.2

At the UPHC \& its field area, convenience sampling was followed for collecting samples from general population as well as additional categories. After an informed written consent, individuals from general population were enrolled without any exception. An effort was made to cover a wide variety of people of different age groups from either sex and from different localities within the field area of the UPHC. However, an effort was specifically made to cover atleast $10 \%$ of individuals from the extremes of the age groups i.e., upto 18 years and above 60 years age. Additional samples from Cases, Contacts of cases and HCWs were also collected separately. Strict confidentiality was ensured at all levels. For the purpose of quality testing and reliability of results, only those laboratories with all necessary equipment and facilities with a valid accreditation, and which routinely undergo external quality assurance were considered. Data analysis was carried out using Microsoft excel and Epiinfo. We herewith share the results for the detailed insight by the scientific community.

\section{RESULTS}

A total of 22514 samples were collected for the purpose of the study, from which a total of 22 samples were rejected by the laboratories due to various reasons. Results were 
thus available for the remaining 22492 samples (Table-1). This included 17026 samples for the general population category and additional samples for the other separate sample categories i.e., Cases, Contacts \& HCWs.

\section{Seropositivity in general population}

The results for general population category (Table-2) shows that as on October 2020, the seroprevalence for the general population in Ahmedabad city had seropositivity of $24.20 \%$ (95\%CI 23.57-24.85). During the previous 2 months \& after the earlier study, the cases had also gone up but the seropositivity recorded just a marginal increase of $0.96 \%$ (from $23.24 \%$ to $24.20 \%$ ). There were 9612 males and 7397 females from the general population whose results were available. A total of 2280 males demonstrated $\mathrm{IgG}$ antibodies giving the positivity of $23.72 \%$. A total of 1837 females demonstrated IgG antibodies giving the positivity of $24.83 \%$. Thus, the percentage positivity is higher among females as compared to the males, however the difference is statistically not significant $(\mathrm{Z}=1.68, \mathrm{P}=0.09)$.

The age of the sample population ranges from 1-94 years $\&$ follows normal distribution. As the age of the enrolled individuals was collected verbally and not verified with any official documents, it typically shows age-heaping bias at every 5 years. (Raw data not shown, only grouped data available in Table-2). The age analysis gives the mode of 30 years, median of 35 years and the mean of $37.26+15.36$ years. The age group wise seropositivity in General population (Figure-1) shows that the positivity for most age-groups is between $20.90 \%-31.00 \%$. Children have higher seropositivity. The seropositivity is comparatively

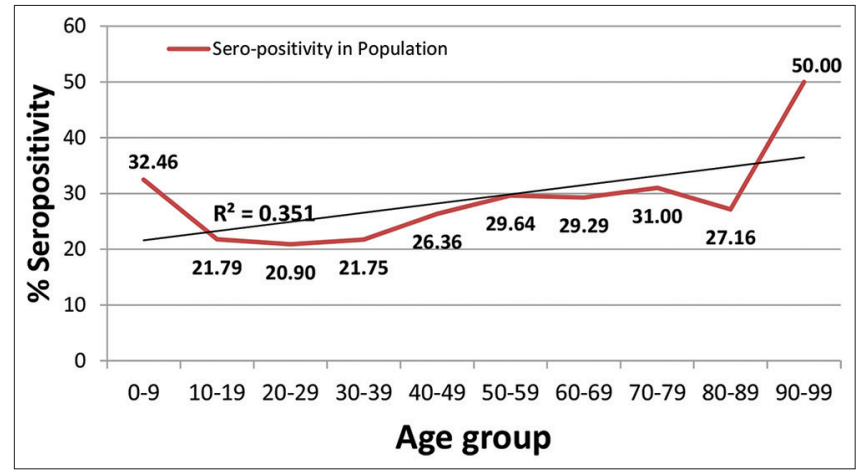

Figure 1: Age group wise seropositivity in general population in Ahmedabad

Table 1: Result of Sero-surveillance

\begin{tabular}{lcccccrr}
$\begin{array}{l}\text { Sample } \\
\text { Category }\end{array}$ & $\begin{array}{c}\text { Total } \\
\text { Samples }\end{array}$ & $\begin{array}{c}\text { Rejected } \\
\text { Samples }\end{array}$ & $\begin{array}{c}\text { Total } \\
\text { Results }\end{array}$ & Positive & Negative & $\begin{array}{c}\text { Indeterminate } \\
\text { Percent } \\
\text { positivity }\end{array}$ \\
\hline $\begin{array}{l}\text { General } \\
\text { Population }\end{array}$ & 17026 & 17 & 17009 & 4117 & 12790 & 102 & 24.20 \\
HCW & 1738 & 1 & 1737 & 362 & 1346 & $23.57-24.85$ \\
Contact & 2039 & 1 & 2038 & 531 & 1489 & $19.00-22.81$ \\
Case & 1711 & 3 & 1708 & 931 & 758 & 20.84 & 19 \\
\hline
\end{tabular}

Table 2: Seropositivity in General population of Ahmedabad

\begin{tabular}{|c|c|c|c|c|c|c|c|c|c|c|}
\hline & \multicolumn{3}{|c|}{ Female } & \multicolumn{3}{|c|}{ Male } & \multicolumn{3}{|c|}{ Total } & \multirow[b]{2}{*}{$\begin{array}{c}\text { Confidence } \\
\text { Interval }\end{array}$} \\
\hline & Results & Positive & $\begin{array}{c}\% \\
\text { Positivity }\end{array}$ & Results & Positive & $\begin{array}{c}\% \\
\text { Positivity }\end{array}$ & Results & Positive & $\begin{array}{c}\% \\
\text { Positivity }\end{array}$ & \\
\hline Total & 7397 & 1837 & 24.83 & 9612 & 2280 & 23.72 & 17009 & 4117 & 24.20 & $23.57-24.85$ \\
\hline \multicolumn{11}{|l|}{ Age group } \\
\hline $0-9$ & 55 & 21 & 38.18 & 59 & 16 & 27.12 & 114 & 37 & 32.46 & $23.99-41.86$ \\
\hline $10-19$ & 567 & 134 & 23.63 & 787 & 161 & 20.46 & 1354 & 295 & 21.79 & $19.67-24.06$ \\
\hline $20-29$ & 2346 & 483 & 20.59 & 2457 & 521 & 21.20 & 4803 & 1004 & 20.90 & $19.78-22.08$ \\
\hline $30-39$ & 1646 & 370 & 22.48 & 2294 & 487 & 21.23 & 3940 & 857 & 21.75 & $20.49-23.07$ \\
\hline $40-49$ & 1223 & 323 & 26.41 & 1550 & 408 & 26.32 & 2773 & 731 & 26.36 & $24.75-28.03$ \\
\hline $50-59$ & 836 & 277 & 33.13 & 1310 & 359 & 27.40 & 2146 & 636 & 29.64 & $27.74-31.60$ \\
\hline $60-69$ & 536 & 167 & 31.16 & 816 & 229 & 28.06 & 1352 & 396 & 29.29 & $26.93-31.77$ \\
\hline $70-79$ & 156 & 51 & 32.69 & 286 & 86 & 30.07 & 442 & 137 & 31.00 & $26.86-35.46$ \\
\hline $80-89$ & 28 & 9 & 32.14 & 53 & 13 & 24.53 & 81 & 22 & 27.16 & $17.87-38.19$ \\
\hline $90-99$ & 4 & 2 & 50.00 & 0 & 0 & 0 & 4 & 2 & 50.00 & $6.76-93.24$ \\
\hline \multicolumn{11}{|l|}{ Zone } \\
\hline $\mathrm{EZ}$ & 1263 & 278 & 22.01 & 1583 & 367 & 23.18 & 2846 & 645 & 22.66 & $21.16-24.24$ \\
\hline NWZ & 680 & 129 & 18.97 & 1520 & 307 & 20.20 & 2200 & 436 & 19.82 & $18.21-21.54$ \\
\hline NZ & 1385 & 397 & 28.66 & 1616 & 427 & 26.42 & 3001 & 824 & 27.46 & $25.89-29.08$ \\
\hline SWZ & 546 & 111 & 20.33 & 903 & 160 & 17.72 & 1449 & 271 & 18.70 & $16.78-20.79$ \\
\hline SZ & 1353 & 385 & 28.46 & 1558 & 427 & 27.41 & 2911 & 812 & 27.89 & $26.29-29.55$ \\
\hline WZ & 1254 & 222 & 17.70 & 1555 & 306 & 19.68 & 2809 & 528 & 18.80 & $17.39-20.28$ \\
\hline
\end{tabular}


low among young adults and shows an increasing trend towards the middle age to elderly.

The zone wise comparison of seroprevalence (Figure-2) shows wide variation from $18.7 \%$ to $33.52 \%$. The zone with high number of initial cases (CZ \& SZ) are showing highest seroprevalence. This is followed by zone with high number of cases during the middle phase of the pandemic (NZ \& EZ) in Ahmedabad. The last to follow are the zones which have high number of cases in recent past (WZ, NWZ \& SWZ).

\section{Seropositivity among health care workers}

With 362 seropositive out of $1737 \mathrm{HCW}$, the seropositivity among the $\mathrm{HCW}$ was estimated to be $20.84 \%$. This is lower than that of the general population $(24.20 \%)$.

\section{Seropositivity in cases}

With 931 seropositive out of total 1708 cases, the seroprevalence of $\operatorname{IgG}$ among cases is $54.51 \%$.

\section{Seropositivity in contacts of cases}

With 531 seropositive contacts out of total 2038 contacts of cases, the seropositivity among the Contact of cases was estimated to be $26.05 \%$. This is lower than that of the cases $(54.51 \%)$ but higher than that of general population \& HCW $(24.20 \%$ \& $20.84 \%$, respectively).

\section{DISCUSSION}

Multiple sero-surveillance studies which have focused on antibodies against SARS-CoV2 have been found to be extremely useful in understanding the progress of the pandemic. Scientifically it is recommended to have continued surveillance to monitor the growing burden of Covid-19. ${ }^{8}$ The seroprevalence varies markedly due to a variety of factors. ${ }^{9}$ For the same reason, understanding the factors affecting immunity is extremely crucial while interpreting the results of the serosurveillance.

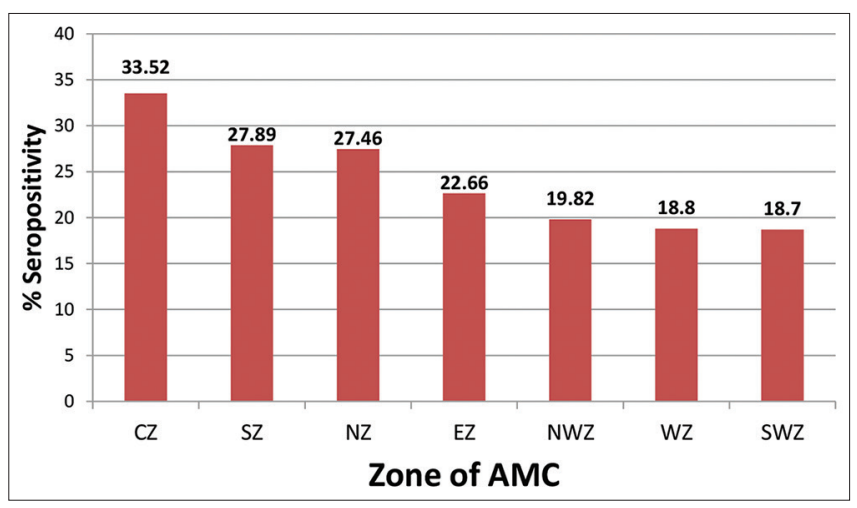

Figure 2: Zone wise seropositivity in Ahmedabad
The present study focuses on the seropositivity among various categories from Ahmedabad city of India as on October 2020. Seropositive individuals are those who demonstrate presence of IgG antibodies against SARSCoV2. Seroprevalence among general population is an important indicator as it gives an idea of cumulative incidence among population and helps in deciding the public health preventive measures for control of the pandemic.

With ongoing pandemic and inspite of high number of cases reported during the previous 2 months (after the previous study), the present study documents a marginal increase in the level of seroprevalence by $0.96 \%$ (from $23.24 \%$ to $24.20 \%$ ). This indicates the possibility of shortterm nature of the $\mathrm{IgG}$ antibodies against SARS-CoV2. The overall seropositivity of $24.20 \%$ in general population also suggest that majority of the general population do not demonstrate the presence of $\operatorname{IgG}$ antibodies against the SARS-CoV2. The proportion of population showing $\operatorname{IgG}$ antibodies suggest that still a large proportion of general population is at risk. Although these numbers are insufficient to comment on the status of herd immunity, it definitely gives indication that the preventive measures must be strongly followed for continued control of the pandemic situation.

The sex wise sero-prevalence in general population is statistically not significant and this is similar to the findings in other studies where it was not found to be significant. . $^{10,11}$ This shows that the pandemic, and the factors affecting immunoglobulin $\mathrm{G}$ levels during the post-covid period are affecting both the gender groups equally. The age group wise analysis shows that children have higher seropositivity as compared to young adults. There is an increasing trend in the seropositivity as the age increases. This may be because of the difference in the symptomatic presentation for people of different age group. Young adults are more likely to have asymptomatic / mild symptomatic presentation. The infection among young adults tends to be less severe and the symptomatic phase stays for shorter duration. ${ }^{12-16}$ The presumed reasons may be confirmed by conducting additional scientific studies looking into these aspects to generate reliable evidence for understanding the reasons for this trend.

The zone wise comparison of seropositivity shows that the zone wise positivity in the general population is closely related to the cases. The earliest and highly affected zones show the highest seropositivity and likewise for the recently affected zones.

Covid19 confirmed cases had 931 positives from 1708 total case and the seropositivity was found to be $54.51 \%$ 
with a confidence interval of $52.14 \%-56.86 \%$. Inspite of being a confirmed case of Covid, exposed to the virus SARS-CoV2, the seropositivity in confirmed cases is $54.51 \%$. This clearly indicates three possibilities. First is that not all the cases develop $\operatorname{IgG}$ antibodies, second possibility is that in many cases their level remains undetectable or the third possibility is that they disappear at some point of time during the post-covid period. Whatever may be the real reason, detailed scientific studies are strongly required to know the reasons for the same.

Comparing the seroprevalence among various groups, it is clear that cases have the highest seropositivity of $54.51 \%$. Contacts of cases are those individuals who are at higher risk of contracting the infection (and thus more likely for developing the IgG antibodies as well). The seropositivity among contacts of cases is $26.05 \%$. Thus, the seropositivity in cases and contacts is in line with the risk for both this category.

The seroprevalence among HCW (20.84\%) shows lower seropositivity as compared to general population $(24.20 \%)$. This may be due to the fact that there are high numbers of cases among general population, increasing the overall risk of the disease for the people, more so in a highly contagious pandemic disease like Covid19. Moreover, the HCW included in our study are not the HCW from designated Covid hospital/s but from the field area/ UPHC. So, these HCW are at low risk compared to HCW posted at Covid hospitals and they are also well informed $\&$ better protected. Thus, on one hand, these workers are more commonly exposed to the risk on account of their occupational exposure in the field area, but, on the other hand they are better informed, well trained and had access to the protective measures. Overall, the seropositivity among all the groups is in line and according to the risk of covid19.

\section{CONCLUSION}

The present study is one of the very few large-scale population-based studies which has also compared the seropositivity among cases, contacts and HCWs apart from the general population. As on October 2020, the sero-positivity for IgG antibodies against Covid19 in Ahmedabad is $24.20 \%$. The seropositivity among various groups is according to the risk of contracting the disease. Not all cases demonstrate $\operatorname{IgG}$ levels and indicate the possibility of undetectable level or disappearing $\operatorname{IgG}$ during the post-covid period. Since the available data is insufficient to comment on the status of herd immunity, the preventive measures must be strongly followed for continued control of the pandemic situation till an effective vaccine is provided to the people at large.

\section{ACKNOWLEDGEMENTS}

We are extremely thankful to respected Dr. Rajiv Kumar Gupta, IAS (Additional Chief Secretary, Government of Gujarat) and Mr. Mukesh Kumar, IAS (Municipal Commissioner, Ahmedabad) for their whole hearted support. This study would not have been possible without the financial support from the authorities of Ahmedabad Municipal Corporation. We acknowledge the full support from the field level health care workers (Corona warriors) who put in great efforts to perform their duties as well as sample collection after informed written consent particularly in a Covid-19 pandemic situation. All the Zonal Deputy Health Officers, Deputy Health Officer (Epidemic), Assistant Health Officers and Medical officers of the Urban Primary Health Centers extended full support in conducting the sero-surveillance. Finally, we are indebted to all the patients including health care workers whose willingness and support has generated the much-desired data for the study.

\section{REFERENCES}

1. Li Q, Guan X, Wu P, Wang X, Zhou L, Tong Y, et al. Early Transmission Dynamics in Wuhan, China, of Novel CoronavirusInfected Pneumonia. N Engl J Med. 2020;382(13):1199-1207. https://doi.org/10.1056/NEJMoa2001316

2. Munster VJ, Koopmans M, Van Doremalen $N$ and Van Riel D. Perspective 692 A Novel Coronavirus Emerging in China A Novel Coronavirus Emerging in China-Key Questions for Impact Assessment. Published online 2020. https://doi.org/10.1056/NEJMp2000929

3. Organization WH. Population-Based Age-Stratified Seroepidemiological Investigation Protocol for COVID-19 Virus Infection, 17 March 2020. World Health Organization; 2020.

4. Hanage WP, Qiu X and Kennedy-Shaffer L. Snowball Sampling Study Design for Serosurveys in the Early COVID-19 Pandemic.; 2020.

https://nrs.harvard.edu/URN-3:HUL.INSTREPOS:37363145

5. Indian Council of Medical Research. Press Release ICMR Advises States to Conduct Sero-Survey to Measure Coronavirus Exposure in the Population Using IgG ELISA Test.; 2020. Accessed February 4, 2021.

https://main.icmr.nic.in/sites/default/files/press_realease_files/ ICMR_PR_IgG_Elisa_30052020.pdf

6. Prakash O, Solanki B, Sheth JK, Joshi B, Kadam M, Vyas S, et al. Assessing seropositivity for IgG antibodies against SARSCoV-2 in Ahmedabad city of India: a cross-sectional study. BMJ Open. 2021;11:44101. https://doi.org/10.1136/bmjopen-2020-044101

7. Sapkal G, Shete-Aich A, Jain R, Yadav PD, Sarkale P, Lakra R, et al. Development of indigenous IgG ELISA for the detection of anti-SARS-CoV-2 IgG. Indian J Med Res. 2020;151(5):444. https://doi.org/10.4103/ijmr.IJMR_2232_20 
8. Lai CC, Wang JH and Hsueh PR. Population-based seroprevalence surveys of anti-SARS-CoV-2 antibody: An upto-date review. Int J Infect Dis. 2020;101:314-322.

https://doi.org/10.1016/j.ijid.2020.10.011

9. Rostami A, Sepidarkish M, Leeflang MMG, Riahi SM, Shiadeh MN, Esfandyari S, et al. SARS-CoV-2 seroprevalence worldwide: a systematic review and meta-analysis. Clin Microbiol Infect. 2020;0(0)

https://doi.org/10.1016/j.cmi.2020.10.020

10. Bryant JE, Azman AS, Ferrari MJ, Arnold BF, Boni MF, BoumY, et al. Serology for SARS-CoV-2: Apprehensions, opportunities, and the path forward. Sci Immunol. 2020;5(47).

https://doi.org/10.1126/sciimmunol.abc6347

11. Stringhini S, Wisniak A, Piumatti G, Azman AS, Lauer SA Bayyson $\mathrm{H}$, et al. Seroprevalence of anti-SARS-CoV-2 IgG antibodies in Geneva, Switzerland (SEROCoV-POP): a population-based study. Lancet. 2020;396(10247):313-319. https://doi.org/10.1016/S0140-6736(20)31304-0

12. Wang $X$, Guo $X$, Xin $Q$, Chu $Y$, Li J, Pan $Y$, et al. Neutralizing Antibodies Responses to SARS-CoV-2 in COVID-19 Inpatients and Convalescent Patients. medRxiv.
2020:2020.04.15.20065623.

https://doi.org/10.1101/2020.04.15.20065623

13. Xiao T, Wang $\mathrm{Y}$, Yuan J, Ye H, Wei L, Liao X, et al. Early viral clearance and antibody kinetics of COVID-19 among asymptomatic carriers. medRxiv. Published online May 2, 2020:2020.04.28.20083139.

https://doi.org/10.1101/2020.04.28.20083139

14. Hu WT, Christina Howell J, Ozturk T, Benameur K, Bassit LC, Ramonell $\mathrm{R}$, et al. Antibody profiles according to mild or severe SARS-CoV-2 infection, Atlanta, Georgia, USA, 2020. Emerg Infect Dis. 2020;26(12):2974-2978. https://doi.org/10.3201/eid2612.203334

15. Whitman JD, Hiatt J, Mowery CT, Shy BR, Yu R, Yamamoto TN, et al. Test performance evaluation of SARS-CoV-2 serological assays. medRxiv. 2020;29:30. https://doi.org/10.1101/2020.04.25.20074856

16. Okba NMA, Müller MA, Li W, Wang $\mathrm{C}$, GeurtsvanKessel $\mathrm{CH}$, Corman VM, et al. Severe Acute Respiratory Syndrome Coronavirus 2-Specific Antibody Responses in Coronavirus Disease Patients. Emerg Infect Dis. 2020;26(7):1478-1488. https://doi.org/10.3201/eid2607.200841

\section{Author's Contribution}

Dr. Om Prakash (OP) Dr. Jay Sheth (JS), Dr. Sheetal Vyas (SV) \& Dr. Aparajita Shukla (AS) conceptualized the study. Dr. Bhavin Solanki (BS), Dr. Ashwin Kharadi (AK) and his team under the guidance of Dr. Om Prakash (OP) planned and carried out the serosurvey. Testing of the samples and reporting was managed by Dr. Mina Kadam (MK) and her team. Data analysis was carried out by Dr. Jay Sheth (JS), Dr. Sheetal Vyas (SV), Dr. Aparajita Shukla (AS). The statistical analysis was done by Dr. Hemant Tiwari (HT). Primary manuscript was prepared by Dr. Omprakash (OP) and Dr. Jay Sheth (JS) and equally contributed by all the other coauthors. All authors contributed to the interpretation of data and approved the final manuscript after critical review.

Work attributed to:

Health Department, Ahmedabad Municipal Corporation.

\section{Orcid ID:}

Dr. Om Prakash - (i) https://orcid.org/0000-0003-0687-3964

Dr. Bhavin Solanki- it https://orcid.org/0000-0002-4609-4992

Dr. Jay Sheth- (1) https://orcid.org/0000-0002-9598-4473

Dr. Ashwin Kharadi- (1) https://orcid.org/0000-0001-9479-0100

Dr. Mina Kadam- (1) https://orcid.org/0000-0001-5473-3961

Dr. Sheetal Vyas- (1) https://orcid.org/0000-0002-2756-6608

Dr. Aparaita Shukla- (D) https://orcid.org/0000-0001-5432-8026

Dr. Hemant Tiwari- (1) https://orcid.org/0000-0002-0379-7479

Source of Funding: None, Conflict of Interest: None. 